Revista Eureka sobre Enseñanza y Divulgación de las Ciencias

ISSN: 1697-011X

revista.eureka@uca.es

Universidad de Cádiz

España

\title{
Méritos académicos e investigación sobre enseñanza de las ciencias
}

Oliva, José María

Méritos académicos e investigación sobre enseñanza de las ciencias

Revista Eureka sobre Enseñanza y Divulgación de las Ciencias, vol. 19, núm. 1, 2022

Universidad de Cádiz, España

Disponible en: https://www.redalyc.org/articulo.oa?id=92068491022

DOI: https://doi.org/10.25267/Rev_Eureka_ensen_divulg_cienc.2022.v19.i1.1001 


\section{Méritos académicos e investigación sobre enseñanza de las ciencias}

Academic merits and research in science education

José María Oliva

Universidad de Cádiz, España

josemaria.oliva@uca.es.

(DD https://orcid.org/0000-0002-2686-6131
DOI: https://doi.org/10.25267/

Rev_Eureka_ensen_divulg_cienc.2022.v19.i1.1001 Redalyc: https://www.redalyc.org/articulo.oa? $\mathrm{id}=92068491022$

Las revistas académicas son una herramienta esencial en el desarrollo del conocimiento, su difusión y transferencia. Prueba de ello es que buena parte de los incentivos económicos y méritos que reciben los investigadores para realizar su labor dependen en gran medida de sus publicaciones en revistas y del impacto que estas poseen. Particularmente, es lo que sucede en el campo de la investigación educativa, donde las revistas acaparan cada vez mayor protagonismo como medio de comunicación.

En el ámbito de la enseñanza de las ciencias experimentales, contamos en lengua española con varias revistas importantes, pero pocas de ellas aparecen indexadas en bases de datos competitivas de acuerdo a los cánones exigidos por las instituciones académicas a efectos de reconocimiento en forma de tramos de investigación, acreditaciones, cobertura de mínimos para tesis por compendio, etc. Aunque en las últimas décadas hemos avanzado bastante en este sentido, todavía se aprecia un importante desequilibrio entre la producción científica con la que afortunadamente contamos y el número de revistas donde publicar en lengua propia, con suficiente repercusión en ese sentido. Y es que, a nuestro modo de ver, existe todavía una excesiva dependencia de criterios basados en la indexación en bases de datos como WoS o Scopus, en detrimento de otras opciones, consideradas "menores" a tales efectos, como el ranking de la FECYT o el de Dialnetmétrica, entre otros, que también ofrecen indicadores útiles para evaluar la calidad de las revistas. Por otro lado, se aprecia una excesiva homogeneidad en los criterios exigidos para distintas facetas de la evaluación, llegándose a pedir como requisitos de publicación para una tesis por compendio en muchas universidades, casi los mismos que se exigen para un sexenio de investigación.

De ahí que sea necesario una profunda revisión de los criterios de evaluación de la actividad investigadora en el ámbito de la educación, en general, y de la didáctica de las ciencias, en particular. De momento, con los que tenemos actualmente, muchas de las revistas españolas que son referentes en nuestro ámbito están quedando fuera de los méritos preferentes que se consideran institucionalmente con suficiente peso en el currículum vitae. Ello nos obliga en muchos casos a publicar en revistas anglosajonas, con escaso eco y transferencia a nuestro sistema educativo, o a intentar hacerlo en revistas de educación generalistas, muchas veces poco interesadas en las didácticas específicas.

Todo ello supone un serio hándicap para la investigación en torno a la enseñanza de las ciencias y, en consecuencia, un claro error a corregir si se quiere apoyar verdaderamente la producción, difusión y transferencia en esta área de conocimiento en nuestro país.

\section{INFORMACIÓN ADICIONAL}

Para citar este artículo: Oliva J. M. (2022). Méritos académicos e investigación sobre enseñanza de las ciencias. Revista Eureka sobre Enseñanza y Divulgación de las Ciencias 19(1), 1001. doi: 10.25267/ Rev_Eureka_ensen_divulg_cienc.2022.v19.11.1001 